\title{
Zinc deficiency may play a crucial role in dialysis- associated bacterial infections
}

\author{
Zahra Lotfi $^{1}{ }^{(\mathbb{D}}$, Abbas Ali Zeraati $^{(\mathbb{D}}$, Elaheh Dashti ${ }^{2}$, Tina Zeraati ${ }^{1^{*}}{ }^{\mathbb{D}}$, Maryam Arghiany $^{1}$, Farnaz \\ Kalani-Moghaddam ${ }^{3}$, Ashkan Haghighi ${ }^{4}$
}

${ }^{1}$ Kidney Transplantation Complications Research Center, Faculty of Medicine, Mashhad University of Medical Sciences, Mashhad, Iran

${ }^{2}$ Department of Internal Disease, Mashhad University of Medical Sciences, Mashhad, Iran

${ }^{3}$ Department of Pediatrician, Mashhad University of Medical Sciences, Mashhad, Iran

${ }^{4}$ Student Research Committee, Faculty of Medicine, Mashhad University of Medical Sciences, Mashhad, Iran

\section{A R T I C L E I N F O}

\section{Article Type:}

Original

\section{Article History:}

Received: 2 July 2020

Accepted: 4 November 2020

ePublished: 21 November 2020

\section{Keywords:}

Chronic kidney disease

End-stage renal disease

Hemodialysis

Infection

Zinc

\begin{abstract}
A B S T R A C T
Introduction: Systemic bacterial infections are a common cause of mortality and morbidity in hemodialysis patients. Zinc has a critical role in several immune system functions. Patients who have enough amounts of zinc are able to better face infections caused by various pathogens in comparison to those with zinc insufficiency.

Objective We sought to assess the role of zinc deficiency in dialysis-associated bacterial infections.

Patients and Methods: Eighty-Three adult patients with end-stage renal disease (ESRD) on hemodialysis including 43 patients with bacterial infectious complications and 40 noninfected patients as well as 41 healthy individuals were enrolled. Clinical data, laboratory values including serum zinc level and imaging findings were collected. SPSS was utilized to analyze the data with a significance cutoff set at $P<0.05$.

Results: Out of 124 participants, 80 (64.51\%) were males and 44 (35.49\%) were females. The mean age of infected hemodialysis group, non-infected hemodialysis group, and healthy controls were $50.8 \pm 16.25,49.1 \pm 18.1$, and $56.3 \pm 18.2$ years, respectively. Catheter site infection (37.3\%) and urinary tract infection (30.2\%) were the most common infections. The mean serum zinc concentration was significantly lower in the infected patients, compared to non-infected patients and healthy individuals $(P<0.001)$.

Conclusion: The ESRD patients on hemodialysis have lower serum zinc levels which are associated with increased risk of bacterial infection. The role of screening for zinc deficiency and use of supplemental zinc in these patients need to be studied.
\end{abstract}

Implication for health policy/practice/research/medical education:

In a study on 83 adult patients with end-stage renal disease (ESRD) on hemodialysis including 43 patients with bacterial infectious complications and 40 non-infected patients as well as 41 healthy individuals, we found mean serum zinc concentration was significantly lower in the infected patients, compared to non-infected patients and healthy individuals $(P<0.001)$. The ESRD patients on hemodialysis have lower serum zinc levels which is associated with increased risk of bacterial infection. The role of screening for zinc deficiency and the administration of supplemental zinc in these patients need to be studied.

Please cite this paper as: Lotfi Z, Zeraati AA, Dashti E, Zeraati T, Arghiany M, Kalani-Moghaddam F, Haghighi A. Zinc deficiency may play a crucial role in dialysis-associated bacterial infections. J Renal Inj Prev. 2022; 11(1): e09. doi: 10.34172/ jrip.2022.09.

\section{Introduction}

Systemic bacterial infections are a common cause of mortality and morbidity in hemodialysis patients. These infections occur more frequently, progress quicker, and show slower recovery rates in hemodialysis patients compared with healthy individuals. A higher vulnerability to infections in these patients is due to the dysfunction of lymphocytes and granulocytes. Additionally, injuries in the skin-mucous barrier might also play a role in higher infection rates (1).

Zinc is an essential mineral with a key role in the immune system. Those with adequate amounts of zinc can 
better eliminate infections caused by various pathogens in comparison to those with zinc insufficiency (2). Zinc deficiency is linked to a wide spectrum of congenital and acquired diseases of the immune system. Experimental studies on animal and human models show that zinc is a critical factor in many aspects of the immune system, ranging from the skin barrier to gene regulation within lymphocytes. Zinc not only affects non-specific immunity by influencing neutrophils and natural killer cell (NKC) activity but also has a major role in specific immunity, impacting both humoral and cellular immunity. Acquired immunity is also affected by zinc deficiency given that zinc is needed for the growth of T lymphocytes and their definitive functions, including activation, Th1 cytokine production, and assistance to $\mathrm{B}$ lymphocytes. Moreover, zinc deficiency is involved in B cell development and antibody production, particularly the production of immunoglobulin G. Zinc deficiency affects macrophages by dysregulating intracellular cytokine production and phagocytosis as well as apoptosis. All the above-mentioned effects of zinc originate from its role in basic cellular functions such as DNA replication, RNA transcription, cell division, and cell activation $(3,4)$. Zinc stimulates white blood cells to evolve into $\mathrm{T}$ lymphocytes with various helpers, suppressors, and NKC functions through activation of the timeline (2). Zinc is also an antioxidant and a membrane stabilizer (5).

Zinc deficiency and infection can cause a vicious cycle in which the presence of either can exacerbate the other. Although the zinc content of most tissues remains normal during chronic kidney disease (CKD), low serum levels have been reported. Considering the high prevalence of bacterial infections in hemodialysis patients and the consequential increase in morbidity and mortality, the high rate of zinc deficiency in such cases, and the role of zinc deficiency in immunologic disorders, it seems likely that the degree of zinc deficiency in hemodialysis patients suffering infections would be greater (6).

\section{Objectives}

We aimed to assess the prevalence of zinc deficiency in hemodialysis patients compared to healthy individuals and to evaluate the association between dialysis-associated bacterial infections and serum zinc levels in these patients

\section{Patients and Methods \\ Study population}

Eighthly-Three adult end-stage renal disease (ESRD) patients who were undergoing hemodialysis in the dialysis center of Imam Reza hospital from January 2017 to December 2018 were enrolled in this cross-sectional study. We included adult patients aged between 18 and 65 years on a routine program of three hemodialysis sessions per week for at least six months. Those with a history of diabetes mellitus, glucocorticoid consumption, signs of malnutrition, positive serologic tests for $\mathrm{HBs}$ antigen, anti-HCV, HIV and HTLV1 antibody, and IgM anti-CMV antibody were excluded.

As the healthy control group, we included 41 healthy age- and gender-matched individuals. Participants were divided into three groups of infected hemodialysis patients $(n=43)$, non-infected hemodialysis patients $(n=40)$, and healthy individuals $(n=41)$.

A complete medical history was taken and a thorough physical examination was performed for each patient. A 20-ml blood sample was collected following a 12-hour fast. Complete blood count (CBC), erythrocyte sedimentation rate (ESR), and serum levels of C-reactive protein (CRP), albumin, bilirubin, alanine aminotransferase (ALT), aspartate aminotransferase (AST), alkaline phosphatase (ALP), urea, creatinine, and glucose were measured. Urine analysis, blood culture, and urine culture were also performed.

Hemodialysis patients with common bacterial infections such as pneumonia, central venous catheter infection, urinary tract infection, and intra-abdominal infections including peritonitis, abscess, and sepsis were included in the infected patient's group. The diagnosis of bacterial infection was made by a single specialist physician based on clinical signs, laboratory data, and radiologic finding where appropriate. The diagnosis was confirmed by the conclusive evidence of infection including positive blood or urine culture alone or positive culture of tissue samples. Patients with any signs of non-bacterial infection (e.g., viral or fungal) were excluded from this group.

Fastingplasmazinclevelsweremeasuredinallparticipants using the atomic absorption spectrophotometer (Model 3030, Perkin Elmer instruments, Shelton, CT, USA) via a heated graphite atomization technique. The samples from all hemodialysis patients were collected before the hemodialysis session. A fasting plasma zinc level of less than $70 \mu \mathrm{g} / \mathrm{dL}$ was considered as zinc deficiency (7). Patients with elevated plasma zinc levels were studied independently for the occurrence of infections.

\section{Statistical analysis}

We used SPSS, version 16 (IBM Statistics, United States) to analyze the collected data. Pearson's correlation test was used to assess bivariate correlations. Chi-square test, independent sample $t$ test, Mann-Whitney $\mathrm{U}$ test, and one-way ANOVA test were applied for intergroup comparisons. The significance level was set at $P<0.05$.

\section{Results}

Out of 83 ESRD patients on hemodialysis, 54 (65\%) were males and 29 (35\%) were females. Of 41 healthy controls, 26 (63.4\%) were males and $15(36.6 \%)$ were females. Table 1 shows the gender distribution of participants. As the table implies, the three groups had no significance in this regard $(P=0.984)$. 
The mean age of infected and non-infected hemodialysis patients was $50.8 \pm 16.25$ and $49.1 \pm 18.1$ years, respectively. Whereas, the mean age of the control group was $56.3 \pm 18.2$ years. The three groups showed no significant difference in terms of age $(P=0.157)$.

The difference in infected and non-infected dialysis patients was not significant $(1.65 \pm 2.59,2.75 \pm 2.39$, $P=0.053)$

Among the infected hemodialysis patients $(n=43)$, the most common infection was catheter infection that involved 16 patients (37.3\%) followed by urinary tract infection (13 patients; $30.2 \%$ ), sepsis (9 patients; $20.9 \%$ ), pneumonia (4 patients; 9.3\%), and abscess (1 patient; 2.3\%) (Table 2).

The difference between the groups of hemodialysis patients was not significant, regarding the distribution of different causes of CKD (0.741). The difference in zinc levels between patients with CKD etiologies was significant $(P=0.016)$ (Table 2$)$.

The mean plasma zinc concentration in patients on hemodialysis was lower than that of the control group, significantly $(69.16 \pm 17.29 \mu \mathrm{g} / \mathrm{dL}$ versus $82.93 \pm 14.75$ $\mu \mathrm{g} / \mathrm{dL} ; P=0.001)$. However, it was not significantly different from the cut-off point of $70 \mu \mathrm{g} / \mathrm{dL}(P=0.66)$. Zinc deficiency (plasma zinc concentration $<70 \mu \mathrm{g} / \mathrm{dL}$ ) was observed in $57.83 \%$ of all the patients undergoing hemodialysis.

Table 3 presents the distribution of zinc deficiency among the three study groups. As shown in the table, the highest prevalence of zinc deficiency was in the infected hemodialysis patients $(74.4 \%)$ followed by non-infected hemodialysis patients $(47.5 \%)$ and the lowest prevalence was observed in healthy controls (34.1\%). The prevalence of zinc deficiency between three study groups was deemed significant $(P=0.001)$ (Figure 1$)$.

The mean plasma zinc level was 59.01 \pm 17.55 , $75.63 \pm 11.56 \mu \mathrm{g} / \mathrm{dL}$ and $82.93 \pm 14.75 \mu \mathrm{g} / \mathrm{dL}$ in the infected patients, non-infected patients, and the healthy controls, respectively $(P<0.001)$. However, the difference was not significant when comparing the non-infected hemodialysis cases with control subjects $(P=0.06)$ (Table 4). The plasma zinc concentration was higher among women in the infected hemodialysis group, while it was higher among men in the other two groups.

Plasma zinc concentration in the ESRD patients was not significantly correlated with age and duration of hemodialysis $(P=0.328$ and $P=0.053$, respectively). However, there was a significant positive correlation between plasma zinc concentration and the daily dose of $\mathrm{EPO}$ in patients under hemodialysis $(\mathrm{r}=0.24, P=0.03)$.

\section{Discussion}

In this study, we examined the relation between dialysisrelated bacterial infections and zinc deficiency. We found that plasma zinc level in infected hemodialysis patients was significantly lower in comparison to the other two groups. However, this difference was not significant when comparing the non-infected hemodialysis cases with healthy controls. The plasma zinc level was highest in our healthy control group.

Bacterial infections have a much higher prevalence in hemodialysis patients in comparison to non-uremic cases and are one of the main causes of hospitalization. Patients undergoing dialysis are highly vulnerable to infections due to disorders of lymphocyte and granulocyte function (8). Zinc is reported to play a crucial role in the immune

Table 1. Gender distribution of hemodialysis patients with and without infection and the control group

\begin{tabular}{|c|c|c|c|c|c|c|c|}
\hline \multirow{2}{*}{ Gender } & \multicolumn{2}{|c|}{ Hemodialysis with infection } & \multicolumn{2}{|c|}{ Hemodialysis without infection } & \multicolumn{2}{|c|}{ Control group } & \multirow{2}{*}{$P^{*}$} \\
\hline & No. & $\%$ & No. & $\%$ & No. & $\%$ & \\
\hline Female & 15 & 34.9 & 14 & 35 & 15 & 36.6 & \\
\hline Male & 28 & 65.1 & 26 & 65 & 26 & 63.4 & 0.984 \\
\hline Total & 43 & 100 & 40 & 100 & 41 & 100 & \\
\hline
\end{tabular}

* According to chi-square test, the $P$ value $<0.05$ was considered significant.

Table 2. Zinc Serum in patients undergone hemodialysis, according to etiology of CKD

\begin{tabular}{|c|c|c|c|c|c|}
\hline Cause of CKD & Zinc level $(\mu \mathrm{g} / \mathrm{dL})$ & $P^{*}$ & Infected patients $(n=43)$ & Non-infected patients $(n=40)$ & $P^{* *}$ \\
\hline Diabetes & $78.2 \pm 6.38$ & \multirow{6}{*}{0.016} & $15(34.9 \%)$ & $13(32.5 \%)$ & \multirow{6}{*}{0.741} \\
\hline Hypertension & $76.8 \pm 8.45$ & & $11(25.6 \%)$ & $10(25 \%)$ & \\
\hline Cardiogenic shock & $71.1 \pm 1.65$ & & $2(4.6 \%)$ & $1(2.5 \%)$ & \\
\hline Glomerulonephritis & $64.6 \pm 3.54$ & & $3(7 \%)$ & $5(12.5 \%)$ & \\
\hline Chronic pyelonephritis & $58.2 \pm 3.33$ & & $4(9.3 \%)$ & $1(2.5 \%)$ & \\
\hline Unknown Causes & $61.7 \pm 9.03$ & & $8(18.6 \%)$ & $10(25 \%)$ & \\
\hline
\end{tabular}

* According to ANOVA test, the $P$ value $<0.05$ was considered significant.

** According to chi-square test, the $P$ value $<0.05$ was considered significant. CKD; chronic kidney disease. 
Table 3. Distribution of zinc deficiency in hemodialysis patients with and without infection and the control group

\begin{tabular}{|c|c|c|c|c|c|c|c|}
\hline \multirow[t]{2}{*}{ Zinc status } & \multicolumn{2}{|c|}{$\begin{array}{c}\text { Hemodialysis patients with } \\
\text { infection }(n=43)\end{array}$} & \multicolumn{2}{|c|}{$\begin{array}{l}\text { Hemodialysis patients without } \\
\text { infection }(n=40)\end{array}$} & \multicolumn{2}{|c|}{ Healthy Controls $(n=41)$} & \multirow[t]{2}{*}{$P^{*}$} \\
\hline & No. & $\%$ & No. & $\%$ & No. & $\%$ & \\
\hline Zinc deficiency & 32 & 74.4 & 19 & 47.5 & 14 & 34.1 & \\
\hline Normal level & 11 & 25.6 & 21 & 52.5 & 27 & 65.9 & 0.001 \\
\hline Total & 43 & 100 & 40 & 100 & 41 & 100 & \\
\hline
\end{tabular}

*According to chi-square test, the $P$ value $<0.05$ was considered significant.

Table 4. Mean plasma zinc level in hemodialysis patients with and without infection and the control group by gender

\begin{tabular}{|c|c|c|c|c|c|c|}
\hline \multirow{2}{*}{ Gender } & \multicolumn{2}{|c|}{$\begin{array}{l}\text { Hemodialysis patients with infection } \\
\qquad(n=43)\end{array}$} & \multicolumn{2}{|c|}{$\begin{array}{l}\text { Hemodialysis patients without infection } \\
\qquad(\mathrm{n}=40)\end{array}$} & \multicolumn{2}{|c|}{ Healthy Controls $(n=41)$} \\
\hline & Mean & SD & Mean & SD & Mean & SD \\
\hline Women & 61 & 19.83 & 72.1 & 11.67 & 76.1 & 7.72 \\
\hline Men & 57.9 & 16.49 & 77.5 & 11.25 & 86.5 & 11.58 \\
\hline Total & 59 & 17.55 & 75.63 & 11.5 & 72.21 & 17.1 \\
\hline
\end{tabular}

SD, Standard deviation.

system (3).

According to a study by Satoshi Shimizu and colleagues, the prevalence of clinical zinc deficiency in the hemodialysis population was about $46.4 \%$. They indicated that even patients who have undergone hemodialysis for a short duration showed signs of zinc deficiency and immune disorders (9). We found a higher prevalence of zinc deficiency among hemodialysis patients (57.83\%). This dissimilarity can be ascribed to the difference in cutoff values for the zinc level. The difference might also be because of the presence of infections in nearly half of the population of our hemodialysis patients.

A study by Skarupskiene et al reported that hemodialysis patients with infectious complications have a significantly higher serum aluminum level and lower zinc levels (10), which is consistent with our findings.

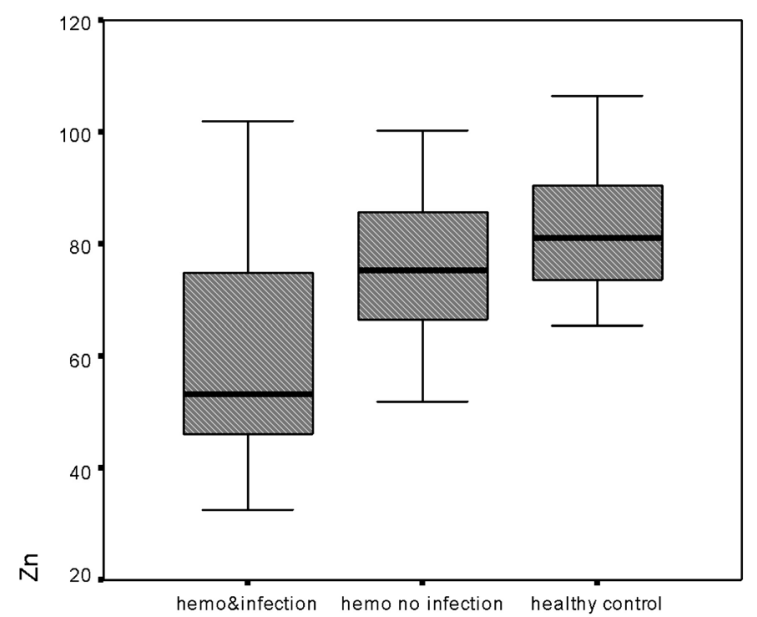

Figure 1. Distribution of zinc ( $\mathrm{Zn}$ ) levels in hemodialysis patients with and without infection and the control group.
Previously, Guo and Wang, showed that treatment with zinc fortification in hemodialysis patients can improve the function of immune cells (11).

Plasma zinc level in the study by Thomson et al was $15.1 \mu \mathrm{mol} / \mathrm{L}$ in the healthy control group and $13.3 \mu \mathrm{mol} / \mathrm{L}$ in the hemodialysis patients, showing a decrease in the latter group (12). In another study conducted in 1979, 68 ESRD patients were compared with 20 healthy controls. Plasma zinc levels were reported as $11.77 \mu \mathrm{mol} / \mathrm{L}$ and $14.48 \mu \mathrm{mol} / \mathrm{L}$, respectively (13). The previous study performed in Brazil in 2004 also reported the plasma zinc level in hemodialysis patients was $71 \mu \mathrm{g} / \mathrm{dL}$ and $78 \mu \mathrm{g} / \mathrm{dL}$ in controls (14). These results are in line with the findings of our study.

In the study by Skarupskiene et al, the mean zinc level in ESRD cases with an infection was $821.9 \mu \mathrm{g} / \mathrm{L}$ and 905.1 $\mu \mathrm{g} / \mathrm{L}$ in the non-infected uremic cases (10). This finding supports the results of our study regarding the lower zinc level in infected ESRD patients compared with noninfected ones.

The effect of zinc deficiency on cellular immunity has been previously described. For instance, the study of Skrajnowska et al showed the impact of supplementation and an optional intake of zinc on immune response and also revealed the effect of this element on cellular immunity(15). Besides, a study in 2017 stated the role of zinc in the occurrence of some infections such as diarrhea and respiratory tract infections (16). In 2013, Lobo et al reported lipid peroxidation and inflammation in hemodialysis patients with a low-zinc level (17).

Decreases in zinc levels and the abnormal metabolism of rare minerals and metals in hemodialysis patients has been evaluated in different studies $(10,18,19)$. In a study conducted in 1991 in Japan, the hemodialysis cases had 
high serum levels of aluminum and copper but showed low zinc and brome concentrations (20). In some other studies, zinc was introduced as a major element in cellular growth and mitosis, since its deficiency greatly affecting the antioxidant defense system $(2,4)$.

In a study in 2013, zinc supplementation in hemodialysis patients led to improved lymphocytic function (11). Although lymphocyte and monocyte count did not differ in general, the cellular function, based on the severity of allergic reactions, showed remarkable improvement with zinc treatment in hemodialysis patients(1).

Based on above-mentioned findings, it can be concluded that patients under hemodialysis are somehow exposed to low-plasma zinc which is associated with remarkably higher rate of infection. Considering that uremic and hemodialysis cases are prone to disorders in various levels of cellular and humoral immunity, which are mostly inevitable, identifying other influencing factors, especially reversible ones, would be highly beneficial. There are some preventable etiologies such as anemia, malnutrition, and a lack of vital minerals such as zinc. These minerals have a crucial role in the performance of the immune system and their modification will result in strengthening the immune system.

\section{Conclusion}

In conclusion, zinc deficiency is associated with bacterial infection in patients undergoing hemodialysis. Plasma zinc level monitoring and supplementation if needed may prevent infection and can be evaluated in further studies. Given the plasma zinc level in hemodialysis patients suffering from infections, it is recommended to closely control plasma zinc levels in such cases and maintain near to normal levels with prescription of supplementary zinc.

\section{Limitations of the study}

There are two major limitations in this study that could be addressed in future research. First, it was a single-center research with a relatively small population. Second, the research is cross-sectional and all data were collected at a single time, and controlling all possible factors that might affect both zinc metabolism and infection in ESRD was not possible. Therefore, future investigations are needed to confirm our results.

\section{Acknowledgments}

The authors thank the Ghaem Hospital Clinical Research Development Unit, for their assistance in this manuscript

\section{Authors' contribution}

$\mathrm{AZ}, \mathrm{ZL}, \mathrm{ED}$ and $\mathrm{TZ}$ were the principal investigators of the study. MA and $\mathrm{AH}$ were included in preparing the concept and design. FK revised the manuscript and critically evaluated the intellectual contents. All authors have read and approved the content of the manuscript and confirmed the accuracy or integrity of any part of the work.

\section{Conflicts of interest}

The authors declare no conflict of financial interest.

\section{Ethical issues}

This research followed the tenets of the Declaration of Helsinki. The study protocols were approved by the institutional ethical committee at Mashhad University of Medical Sciences (Ref\#99/14844). Accordingly, all the patients were informed about the research and the consent was taken from them before any intervention. This study was extracted from the residential thesis of Elaheh Dashti in the department of internal medicine at this university (Thesis \#1964). Moreover, ethical issues (including plagiarism, data fabrication, double publication) have been completely observed by the authors.

\section{Funding/Support}

This study was supported by a research project (in Mashhad Research Centre of Nephrology), as an internal medicine residential dissertation, in Mashhad University of Medical Sciences (Grant \# 85206).

\section{References}

1. Maares M, Haase H. Zinc and immunity: An essential interrelation. Arch Biochem Biophys. 2016;611:58-65. doi: 10.1016/j.abb.2016.03.022.

2. Hojyo S, Fukada T. Roles of Zinc Signaling in the Immune System. J Immunol Res. 2016;2016:6762343. doi: $10.1155 / 2016 / 6762343$.

.3 3 .. Wessels I, Maywald M, Rink L. Zinc as a Gatekeeper of Immune Function. Nutrients. 2017;9:1286. doi: 10.3390/ nu9121286.

4. Baltaci AK, Yuce K, Mogulkoc R. Zinc Metabolism and Metallothioneins. Biol Trace Elem Res. 2018;183:22-31. doi: 10.1007/s12011-017-1119-7.

5. Chasapis CT, Ntoupa PA, Spiliopoulou CA, Stefanidou ME. Recent aspects of the effects of zinc on human health. Arch Toxicol. 2020;94:1443-60. doi: 10.1007/s00204-020-027029.

6. Fraker PJ, King LE, Laakko T, Vollmer TL. The dynamic link between the integrity of the immune system and zinc status. JNutr. 2000;130:1399S-406S. doi: 10.1093/jn/130.5.1399S.

7. Chasapis CT, Loutsidou AC, Spiliopoulou CA, Stefanidou ME. Zinc and human health: an update. Arch Toxicol. 2012;86:521-34. doi: 10.1007/s00204-011-0775-1.

8. Pappas EM, Mpournaka S, Katopodis P, Chardalias A, Tsakas S, Theodoros T, et al. The effect of dialysis modality and membrane performance on native immunity in dialysis patients. Pril (Makedon Akad Nauk Umet Odd Med Nauki). 2019;40:25-32. doi: 10.2478/prilozi-2019-0011.

9. Shimizu S, Tei R, Okamura M, Takao N, Nakamura Y, Oguma H, Maruyama T, Takashima H, Abe M. Prevalence of zinc deficiency in Japanese patients on peritoneal dialysis: comparative study in patients on hemodialysis. Nutrients. 2020;12:764. doi: 10.3390/nu12030764. 
10. Skarupskiene I, Kuzminskis V, Abdrachmanovas O, Ryselis S, Smalinskiene A. Cinko ir aliuminio kiekio hemodializuojamu ligoniu kraujyje itaka infekciniu komplikaciju dazniui [Zinc and aluminum concentrations in blood of hemodialysis patients and its impact on the frequency of infections]. Medicina (Kaunas). 2005;41 Suppl $1: 65-8$.

11. Guo CH, Wang CL. Effects of zinc supplementation on plasma copper/zinc ratios, oxidative stress, and immunological status in hemodialysis patients. Int J Med Sci. 2013;10:79-89. doi: 10.7150/ijms.5291.

12. Thomson NM, Stevens BJ, Humphery TJ, Atkins RC. Comparison of trace elements in peritoneal dialysis, hemodialysis, and uremia. Kidney Int. 1983;23:9-14. doi: 10.1038/ki.1983.3.

13. Zumkley H, Bertram HP, Lison A, Knoll O, Losse H. Aluminum, zinc and copper concentrations in plasma in chronic renal insufficiency. Clin Nephrol. 1979;12:18-21.

14. Ribeiro RC, Sales VS, Neves Fde A, Draibe S, Brandão-Neto J. Effects of zinc on cell-mediated immunity in chronic hemodialysis patients. Biol Trace Elem Res. 2004;98:20918. doi: 10.1385/bter:98:3:209.

15. Skrajnowska D, Bobrowska-Korczak B. Role of zinc in immune system and anti-cancer defense mechanisms. nutrients. 2019;11:2273. doi: 10.3390/nu11102273.

16. Gammoh NZ, Rink L. Zinc in Infection and Inflammation. Nutrients. 2017;9:624. doi: 10.3390/nu9060624.

17. Lobo JC, Stockler-Pinto MB, Farage NE, Faulin Tdo E, Abdalla DS, Torres JP, Velarde LG, Mafra D. Reduced plasma zinc levels, lipid peroxidation, and inflammation biomarkers levels in hemodialysis patients: implications to cardiovascular mortality. Ren Fail. 2013;35:680-5. doi: 10.3109/0886022X.2013.789960.

18. 18. Broman M, Bryland A, Carlsson O; T-Trace Acute Study Group. Trace elements in patients on continuous renal replacement therapy. Acta Anaesthesiol Scand. 2017;61:650-659. doi: 10.1111/aas.12909.

19. Gómez de Oña C, Martínez-Morillo E, Gago González E, Vidau Argüelles P, Fernández Merayo C, Álvarez Menéndez FV. Variation of trace element concentrations in patients undergoing hemodialysis in the north of Spain. Scand J Clin Lab Invest. 2016;76:492-9. doi: 10.1080/00365513.2016.1201852.

20. Hosokawa S, Oyamaguchi A, Yoshida O. Trace elements and complications in patients undergoing chronic hemodialysis. Nephron. 1990;55:375-9. doi: 10.1159/000186003.

Copyright (C) 2022 The Author(s); Published by Nickan Research Institute. This is an open-access article distributed under the terms of the Creative Commons Attribution License (http://creativecommons.org/licenses/by/4.0), which permits unrestricted use, distribution, and reproduction in any medium, provided the original work is properly cited. 